\title{
ABLE in Afghanistan
}

\section{Nancy Hatch Dupree has dedicated a lifetime to documenting and preserving Afghanistan's cultural heritage}

\author{
By Carol A. Erickson | December 9, 2009
}

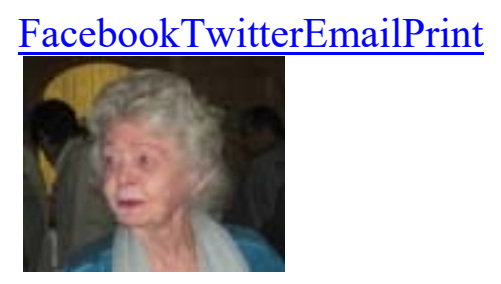

Blue-eyed octogenarian and information advocate Nancy Hatch Dupree is a rare bright spot in Afghanistan today. But the impact of her work can only be fully appreciated in its brutally unglamorous context.

The 2009 Afghan presidential elections were lengthy and disappointing, highlighting the extreme levels of corruption that are endemic in this war-torn nation of 31 million. Three decades of fighting and instability have led to a near-complete breakdown in the educational system, with many educated Afghans fleeing the country. Partner this with indifference or even active hostility to secular education among many rural populations and the result is literacy rates estimated at $28 \%$ at best, or some say more accurately, $15 \%$.

While the U.S. government's Agency for International Development (USAID) has spent over $\$ 6.9$ billion in aid to Afghanistan since 2002, less than 6\% of those funds are dedicated to education, with major improvements still needed. Many schools are conducted in tents or under the shade of trees, with school buildings operating only in selected urban areas. With shortages of pens, pencils, paper, and textbooks, school libraries are a dreamed-of luxury afforded to only a few.

The education sector is perennially underfunded, receiving scarcely $10 \%$ of what other sectors receive. The Ministry of Culture and Youth governs the country's few remaining public libraries, but its budget is miniscule and largely devoted to salaries. Money for acquisitions is virtually nonexistent.

Access to information and books in Afghanistan has been in crisis for years: There is no national library. Much of the Kabul University Library was destroyed during the civil war and Taliban years, but now operates, albeit with outdated collections, with no automation, no heat, and very few computers. The National Archive of Afghanistan is plagued by preservation challenges, with no heat, electricity, or climate control, and an infestation of insects that are destroying the collections. And there is almost no publishing industry. 


\section{Before the war}

Prior to the wars, every government ministry in the Afghan capital of Kabul had its own library with collections of great importance. Most of those collections no longer exist, having become sources for heat to fuel stoves during times when wood was scarce, or sold in bazaars at bulk weight to make bags used by shopkeepers.

This dismal state of affairs served as a backdrop to a September 15, 2009, Capitol Hill reception and celebration of the work of Nancy Hatch Dupree by President Barack Obama's Special Representative to Afghanistan and Pakistan Richard Holbrooke. Dupree has dedicated a lifetime to documenting and preserving Afghanistan's cultural heritage. She has spearheaded an effort to develop the Afghan Center at Kabul University ( $\underline{\mathrm{ACKU}})$, currently the most modern library in the country, as well as the ACKU Box Libraries Extension (ABLE), which has placed more than 230,000 books throughout 215 rural sites in 32 of Afghanistan's 34 provinces. Holbrooke admitted that until the reception he had never met Dupree nor seen her Afghanistan work firsthand, but praised her effort as an example of what can be accomplished by individuals. He also noted that while he wished the U.S. government had funding for good work such as Dupree's, the government's resources were not adequate to supplement all private efforts undertaken in the region.

At the age of 83, Dupree is articulate and passionate about the country in which she has worked for over 40 years. She admits that her foray into Afghanistan was "sort of an accident." Dupree initially arrived in Kabul in 1962 as a diplomat's wife, fell into writing guidebooks, and then married archaeologist Louis Dupree. She traveled extensively around the country until she and her husband were expelled in 1978, and relocated to Pakistan.

When the Soviet-Afghan war ended, Dupree was able to resume her work in Afghanistan. Dozens of nongovernmental organizations (NGOs) followed, all implementing uncoordinated efforts to try to rebuild the county. Recognizing the chaos, the United Nations launched Operation Salam (Peace) to better coordinate humanitarian and economic assistance to Afghanistan through the establishment of various committees on health, human resources, etc. The U.N. asked Dupree and her husband to serve on Operation Salam's library committee and informed them that the committee's ambitious goal was to purchase every single book that had ever been written about Afghanistan. The Duprees recognized the illogicality of this request, but regardless, Louis Dupree compiled a comprehensive Afghan book list. He wanted to demonstrate that not only was it impossible to afford to purchase all of those resources, but that even if the U.N. had the funds, there was no place in Afghanistan to house such a collection. In addition, because of low literacy rates and the resources printed in languages other than the local Dari or Pashto, clients of the library could realistically use only about $1 \%$ of the resources.

Instead, the Duprees proposed a pragmatic approach to the committee: to collect the practical materials, reports, and "lessons learned" that NGOs developed when trying to rebuild the country, as well as locally published materials in local languages. Thus, in 1989, the library committee established the precursor to ACKU, the Afghan Resource and Information Center. Dupree chuckles good-naturedly as she reflects on the beginnings of this project. "We didn't know anything about how to run a library or how to catalog. We started with nothing, got a bit 
more organized, and while we realized that we were collecting all of the documents needed by the NGOs, at the same time, we recognized there were information needs elsewhere."

\section{Enlightenment in the pages of a book}

Dupree traveled to a northern Afghan community in the early 1990s for an unexpected transformational encounter. While visiting a refugee camp, she met a beautiful teenage girl who picked up a book and whispered, "Once I could read that." Her heart almost broke, Dupree says. It was this recognition of the lack of attention to rural and refugee populations that inspired Dupree to initiate the mobile book extension component of ACKU. Each mobile box on wheels contains about 200 books that are distributed to the provinces via the NGOs working there. The local community decides how to manage those boxes, which stay in the community and are periodically updated with more books from ACKU.

Dupree says, "There is nothing sadder than going into a provincial school with all of these bright-eyed girls and boys and seeing there is no information for them beyond the official curriculum - nothing on agriculture or health." It was this fact that caught the imagination of donors, and Dupree began her efforts to secure grants to provide Afghan schools with print resources via the ABLE mobile book initiative.

Dupree and her colleagues asked ABLE users to tell them what subjects they wanted to read about. Their answers were unpredictable: Why do we have earthquakes in Afghanistan? What kind of industries should we develop as sustainable businesses?

The ACKU Board of Editors compiled the list of subjects that the general public suggested and then found an author to write 100 pages or less in simple Dari or Pashto on each topic. To date, ACKU has published over 80 titles, the first a book on geography to address the schools' lack of curriculum on the subject. Other published topics include Afghan history, the environment, beekeeping, raising chickens, eye care, and good health practices. ACKU now has an average of 1,000 printed copies each in Dari and in Pashto of each of these books, with over 200,000 books published to date.

And it didn't stop there. Dupree worried about the Afghan provincial councils, who were supposed to be channeling recommendations and requests to the national government based on community needs and the newly established Afghan constitution. The problem was that no one had provided the councils with copies of the constitution, and they had no idea what laws had been passed by the Afghan parliament. Judges were making decisions in court cases based on their memory of what the law was, and not on actual written sources.

\section{Democracy requires access}

Dupree's approach was once again pragmatic. "If you're going to have any democracy, people have to have access to the constitution. We got copies of the constitution and the laws passed by the parliament and distributed them." This was one of many revelations that no one was taking the time to ask the Afghan people about their information needs. 
The Embassy of Afghanistan in Washington, D.C.,was not able to specify the exact amount of money dedicated to library development in the country; however Ambassador Said Jawad said, "Afghans realize the personal enlightenment available within the pages of a book and value the true, personal freedom that arrives only through education and literacy."

ACKU currently operates in a cramped but very popular space within the Kabul University Library. It offers a pleasant reading room, professional staff, and computer access to multimedia collections. Its stacks are bursting but the library is trying to digitize many of the records for preservation purposes. Built over decades, the collection is unique in the world and was protected in Pakistan during the Taliban years when all else was destroyed. Of particular interest is a collection of Taliban newspapers in English.

Because of the limited space for ACKU, Dupree's current focus is the construction a new permanent ACKU structure at the Kabul University campus on land donated by Afghan President Hamid Karzai. Scheduled to open in late 2010, the center will house over 50,000 documents; provide access to computers, databases, and the internet; conduct various educational programs, and continue its ABLE outreach project.

\section{Strategy often ignores the obvious}

Mary Nell Bryant, who served as the U.S. State Department's information resource officer for Afghanistan and Pakistan from 2007 to 2009, says, "There is nothing else even remotely like it. ACKU is the most comprehensive collection of materials on Afghanistan that exists anywhere. It is the de facto National Library. In addition, its ABLE book box program is one of the few attempts to bring library-type services to the outer reaches of Afghanistan."

Bryant reports that the U.S. Embassy in Afghanistan has established seven "Lincoln Centers" throughout the country that have public reading rooms; meeting space for discussions and classes; and books, magazines, English-language learning materials, children's books, documentaries, and subtitled American feature films.

Bryant also stresses the challenge of providing materials in the local languages. "Everywhere we went people kept asking us if we could obtain books for them in Dari or Pashto. The Farsi language of Iran is very similar to Dari, and the Iranian publishing community is robust, but the U.S. Embassy was prohibited from obtaining Farsi materials from Iran due to the economic sanctions imposed by the U.S. government."

Dupree stresses the critical need for more local-language materials as well. "There are organizations providing huge numbers of book donations in English that are never taken off the shelves. Our books are scruffy looking because they are read, while the English books are in pristine condition because no one uses them."

When asked why international aid organizations do not include information access and books as a mandatory component of their work, Dupree responds, "Because it means more money, more thinking, and more work. They love quick fixes to get in and get out." She spoke of one multilateral organization that had a goal of training 600,000 adults to read, but after the training 
was completed, did not provide a single book for the new readers, guaranteeing that their skills would rapidly deplete.

In 2009 Dupree wrote, "Every sector, from economics to microfinance, agriculture to industry, health to education, or human rights to governance can benefit from stimulating learning opportunities. Readers may wonder why such a simple observation needs repeating. Simple it may be, but high-sounding strategy papers too often ignore the obvious. Short-term fact-finding missions avidly collect data, write profound analysis, propose expensive recommendations, and launch quick fixes, only to omit sustainable components that would supply players with the knowledge they need to keep programs afloat."

Dupree is passionate about Afghanistan's future. "I want people to understand that there is potential in this country. Afghans are very courageous and have been through a long period of war, but they have a very strong culture of their own that they've adhered to. We need to help them survive, but we need to do it without imposing another culture on them. We need to help strengthen their culture, not adopt a Western one, by sharing information about their past. A high proportion of the population is younger and learned during the refugee period to be more politically conscious. It is possible for them to raise their voices, but we need to give them the information they need so that they can speak with intelligence."

Given Dupree's expertise in Afghanistan, one can only hope that the international aid community will take the time to sit down with her and incorporate her recommendations and decades of hands-on experience with libraries, books, and publishing into aid programs for Afghanistan moving forward. She can be contacted at: dupreefoundation@gmail.com. More information about the work of the Afghan Center at Kabul University can be found here, and tax-deductible donations can be made at www.dupreefoundation.org/.

Carol A. Erickson, president of Carol A. Erickson Associates in Arlington, Virginia, has spent over 20 years working on issues of international librarianship. She has held key positions at Read Global, the Bill and Melinda Gates Foundation, the American Library Association, and IREX: International Research and Exchanges Board. 